\title{
A methodological approach for energy demand assessment: theoretical analysis on solar thermal collector energy contribution
}

\author{
Domenico Palladino ${ }^{1,}{ }^{*}$, Carmen Lavinia ${ }^{1}$, Francesca Margiotta $^{1}$ and Francesca Pagliaro ${ }^{1}$ \\ ${ }^{1}$ Italian National Agency for New Technologies, Energy and Sustainable Economic Development \\ (ENEA), DUEE Department, 00123 via Anguillarese 301 Santa Maria di Galeria (Rome), Italy
}

\begin{abstract}
Solar thermal collector system is a widely used solution involving renewable energy source to cover the energy demand for domestic hot water production. At Italian level, the UNI TS 11300 provides a calculation methodology based on two approaches: the asset rating, which is easy to be applied but provides approximated results, and the tailored rating, which is more reliable but requires several detailed information. In this context, the present work proposes a new methodological approach to develop a simplified calculation method in order to obtain accurate energy performance results with no-additional cost for assessors and final users. Different case studies were analysed carrying out parametric simulations. The obtained results have led to the definition of the new simplified calculation methodology to predict the thermal energy supplied by solar thermal collectors; it allows also calculating the domestic hot water volume to be covered by other technical building systems, becoming a useful tool for their pre-dimensioning. Besides, the results open to new scenarios of interest, such as the application of the same approach to other energy services in order to integrate the outcomes of the asset rating provided by the UNI TS 11300.
\end{abstract}

\section{Introduction}

The use of Renewable Energy Sources (RES) is an effective solution to reach the goal of $\mathrm{CO}_{2}$ emission reduction set by the European Union (EU). Among the EU Member States (MSs), Italy ranks $3^{\text {rd }}$ in terms of RES contribution in covering energy consumption [1]. In 2019 the thermal energy supplied by RES is increased up to $19.7 \%$ of total thermal energy use [2] confirming the achievement of the Italian target by 2020 (17\%). Furthermore, the Integrated National Energy and Climate Plan [3] has introduced the ambitious target of 30\% of RES coverage by 2030 . Several national strategies and measures were drawn up including requirements and incentives for RES use, such as Energy Efficiency Certificates, Conto Termico, and tax deductions.

\footnotetext{
* Corresponding author: domenico.palladino@enea.it
} 
In this context, one of the most adopted solutions is the use of solar thermal collector (STC) system to cover the Domestic Hot Water (DHW) production [1] whose installation is increased of $23 \%$ compared to 2014, especially in the residential sector (about $74 \%$ ) [2].

The calculation of STC performance is an important topic widely studied in the Literature. Many previous studies involved the use of dynamic simulation software in the evaluation of STC energy production. Valdiserri et al. [4] carried out an energy analysis in different Italian cities considering the DHW production covered by STCs coupled with a storage tank and a recirculation loop. In [5] and [6] the use of STCs was simulated under realistic weather data (Morocco and Tunisia, respectively) demonstrating the influence of daily DHW consumption on the performance of STC systems. Chow et al. [7] used a dynamic simulation software to compare the thermal energy performance of two common types of STCs, while Hazami et al. [8] used a dynamic numerical tool for studying the convenience of STC system for DHW production with respect to other standard technologies under Tunisian weather conditions. In [9] dynamic simulations were used for optimizing STC array in Thessaloniki and in [10] the building integration with STCs was investigated as a refurbishment measure of buildings. Thermal performance analyses of STCs were also carried out by using and comparing different solvers: in [11] numerical simulations of STC system composed of two flat plate collectors, a water tank for heat storage, and a coil heat exchanger were performed using a code written in Matlab programming language and in TRNSYS software. In [12], instead, DHW supplied by STCs was analysed by means of a dynamic approach (Simulink model) and an F-chart method capable of evaluating the produced monthly thermal energy. In [13] a procedure for the calculation and optimization of STC performance was written in Matlab programming language obtaining four new parameters to evaluate the system performance.

As highlighted in the previous studies, the accurate assess of the STC energy production was mainly obtained by means of dynamic tools and code implementation that often require specific technical skills and detailed information about TBSs.

In this context, the development of a simplified methodology depending on a few information could be a useful tool not only in STC initial analyses and STC predimensioning, but also for the preliminary evaluation for incentive assessment.

Basing on this premise, the present work aims to find a new simplified calculation method capable of assessing the thermal energy demand supplied by STCs, the volume of DHW ( $\mathrm{V}_{\text {DHW }}$ ) provided by STC system, and the remaining $\mathrm{V}_{\text {DHW }}$ to be covered by other TBSs in agreement with UNI TS 11300 part 4 [14], i.e. the current national regulation which provides the calculation method.

\section{Materials and Methods}

\subsection{Calculation method provided by the national standard}

The implementation of the UNI EN 15316-4-3 [15], the UNI TS 11300 part 1 [16], and especially the UNI TS 11300 part 4 [14], provides the methodology to assess the monthly DHW primary energy need to be covered by STC system. This methodology is based on technical characteristics of STC panels and on outdoor thermal conditions. In particular, according to [14], the monthly thermal energy production (QSTC,month) for STCs with same technical characteristics, orientation, and inclination and connected in parallel to each other, can be evaluated with equation 1, where the two dimensionless parameters $\mathrm{X}$ and $\mathrm{Y}$ are expressed by equation 2 and equation 3, respectively.

$$
Q_{S T C, \text { month }}=\left(a \cdot Y+b \cdot X+c \cdot Y^{2}+d \cdot X^{2}+e \cdot Y^{3}+f \cdot X^{3}\right) \cdot Q_{D H W, \text { mont }}
$$




$$
\begin{gathered}
X=\frac{A \cdot U_{L O O P} \cdot \eta_{L O O P} \cdot \Delta T_{\text {ref }} \cdot f_{s t} \cdot t_{m}}{10^{3} \cdot Q_{D H W, S T C, \text { month }}} \\
Y=\frac{A \cdot I A M \cdot \eta_{0} \cdot \eta_{L O O P} \cdot I_{m} \cdot t_{m}}{10^{3} \cdot Q_{D H W, S T C, \text { month }}}
\end{gathered}
$$

In agreement with [14], the $\mathrm{Q}_{\mathrm{STC}, \text { month }}$ is function of the following parameters:

1. Correlation factors (a, b, c, d, e, and f);

2. Monthly DHW thermal energy need of the building ( $\mathrm{Q}_{\mathrm{DHW}, \mathrm{month}}$ );

3. Two correction factors of STC efficiency $\left(\eta_{0}\right)$ and of incidence angle modifier (IAM) depending on technical characteristic of STC system;

4. Net area of STCs (A);

5. Heat loss coefficient $\left(\mathrm{U}_{\mathrm{LOOP}}\right)$ and efficiency ( $\left.\eta_{\mathrm{LOOP}}\right)$ of STC system;

6. Correction factor $\left(\mathrm{f}_{\mathrm{st}}\right)$ depending on storage capacity;

7. Number of operating hours of STCs during each month $\left(t_{m}\right)$;

8. Monthly Irradiance $\left(\mathrm{I}_{\mathrm{m}}\right)$ on the collector panel;

9. Reference temperature difference $\left(\Delta \mathrm{T}_{\mathrm{ref}}\right)$ between the water operational temperature $\left(40^{\circ} \mathrm{C}\right)$ and the water temperature inside the STCs, which depends on the average outdoor temperature;

10. Monthly DHW energy need to be covered by STCs (QDHW,STC,month).

The equations 1-3 allow assessing the thermal energy need covered by STCs only knowing several detailed information including the configuration of the Technical Building System (TBS).

\subsection{Methodological approach}

The proposed methodological approach was developed carrying out parametric simulations in order to obtain a simplified, but accurate mathematic correlation between the current methodologies, the asset rating (AR) and the tailored rating (TR). Several case studies were defined varying the main parameters that influence the thermal energy produced by the STCs. The numerical analyses were performed by using Edilclima that is an energy software certified by the Italian Thermotechnical Committee (CTI) according to the national regulation framework.

The energy need to produce the $\mathrm{V}_{\text {DHW }}$ was analysed considering only the residential stock since the DHW energy need is usually negligible in the non-residential sector, according to [16] and [14]. Furthermore, STC systems are mainly installed in residential buildings.

According to [14], STC energy production mainly depends on weather conditions, number of solar panels and their technical characteristics, and energy need for the $\mathrm{V}_{\mathrm{DHW}}$ production. For this reason, different locations and technical configurations were taken into account to define the case studies.

More in detail, the $\mathrm{V}_{\mathrm{DHW}}$ was initially assumed as $1,000 \mathrm{l} /$ day $\left(\mathrm{V}_{\mathrm{DHWlim}}\right)$ in order not to reach $100 \%$ of the coverage by STCs and to achieve a different energy coverage varying both number of panels and weather conditions. According to this assumption, a corrective factor, function of the $V_{\text {DHWlim }}$ and the $V_{\text {DHW }}$ calculated with the $A R$, was introduced in the final mathematical equation. Besides, the proposed calculation method was also validated considering different values of $V_{\text {DHW }}$ obtained from the $A R$ and the TR.

The flowchart of the methodological approach adopted in order to find the simplified calculation method for the STCs energy assessment is shown in Fig. 1.

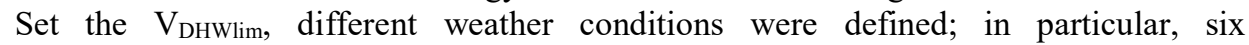
representative Italian cities were chosen in order to cover the heterogeneity of the national climatic context (Table 1). 
According to [14], the outdoor conditions mainly affect the DHW production of the STCs in two ways: the outdoor air temperature influences the temperature reached by DHW $\left(\mathrm{T}_{\mathrm{H} 2 \mathrm{O}}\right)$, while the average monthly irradiance $\left(\mathrm{I}_{\mathrm{m}}\right)$ influences the thermal energy production. In order to take into account both these quantities, a new parameter, namely Climatic Parameter (CP), was defined representing the product of $\mathrm{T}_{\mathrm{H} 2 \mathrm{O}}$ and $\mathrm{I}_{\mathrm{m}}$ for each considered location.

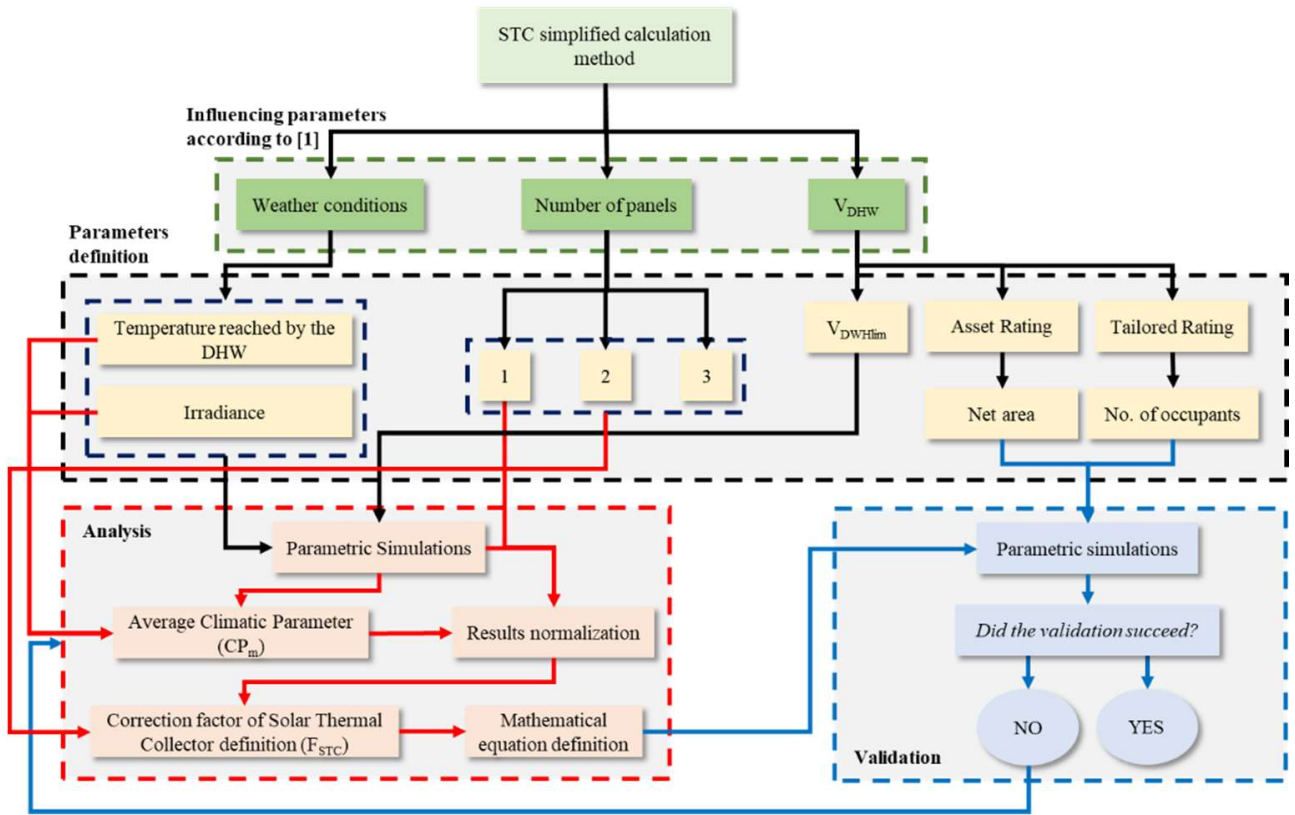

Fig. 1. Flowchart of the methodological approach.

Table 1. Selected Italian location (processing from data by [17]).

\begin{tabular}{|c|c|c|c|c|c|c|}
\hline \multirow{2}{*}{ Location } & \multirow{2}{*}{$\begin{array}{l}\text { Climatic } \\
\text { zone }\end{array}$} & \multirow{2}{*}{$\begin{array}{l}\text { Degree } \\
\text { Days }\end{array}$} & \multicolumn{3}{|c|}{ Outdoor temperature $\left[{ }^{\circ} \mathrm{C}\right]$} & \multirow{2}{*}{$\begin{array}{c}\text { Average annual } \\
\text { irradiance } \\
{\left[\mathbf{M J} / \mathbf{m}^{2}\right]}\end{array}$} \\
\hline & & & Winter & Summer & $\begin{array}{r}\text { Thermal } \\
\text { excursion }\end{array}$ & \\
\hline Palermo & $\mathrm{B}$ & 751 & 5.0 & 32.6 & 6.5 & 15.6 \\
\hline Naples & $\mathrm{C}$ & 1034 & 2.0 & 32.4 & 10.5 & 14.8 \\
\hline Bari & $\mathrm{C}$ & 1185 & 0.0 & 32.3 & 8.0 & 14.3 \\
\hline Rome & $\mathrm{D}$ & 1415 & 0.0 & 34.0 & 11.0 & 15.6 \\
\hline Bologna & $\mathrm{E}$ & 2259 & -5.0 & 33.0 & 12.0 & 12.7 \\
\hline Milan & $\mathrm{E}$ & 2404 & -5.0 & 31.9 & 12.0 & 13.0 \\
\hline
\end{tabular}

Since the energy supplied by the collectors increases with the number of panels, up to cover $100 \%$ of the energy need, different configurations of STCs were considered varying the number of panels according to ISTAT data [18]: ST1 (1 panel), ST2 (2 panels), and ST3 ( 3 panels). For the sake of clarity, Fig. 2 shows the monthly values of the thermal energy supplied by the STCs (MESTCs) for each location and configuration of STCs, highlighting the great impact that these two parameters have on STC energy production.

Finally, basing on these preliminary considerations, different values of the $\mathrm{V}_{\text {DHW }}$ were defined considering both the AR and the TR; these values were applied in the final energy simulations, which results were used to validate the obtained equations. In the AR, the current 
methodology provided by [19] makes the $\mathrm{V}_{\mathrm{DHW}}$ depending on the building net area; the TR, instead, considers the $\mathrm{V}_{\text {DHW }}$ basing on the number of occupants. For these reasons, in the first case, the most common net areas for national residential buildings were chosen according to ISTAT census $\left(80 \mathrm{~m}^{2}, 100 \mathrm{~m}^{2}, 120 \mathrm{~m}^{2}, 135 \mathrm{~m}^{2}\right.$, and $\left.168 \mathrm{~m}^{2}\right)$; for the second one, instead, three tailored $\mathrm{V}_{\mathrm{DHW}}$ configurations were adopted depending on the number of occupants (1, 2 or 3 people respectively). The average $V_{\text {DHW }}$ per person $(1721 /$ day $)$ was evaluated considering a standard use of sanitary appliances combining the related Literature data [20, 21]. The adopted $V_{D H W}$ for the $A R$ and the TR configurations are shown in Table 2.

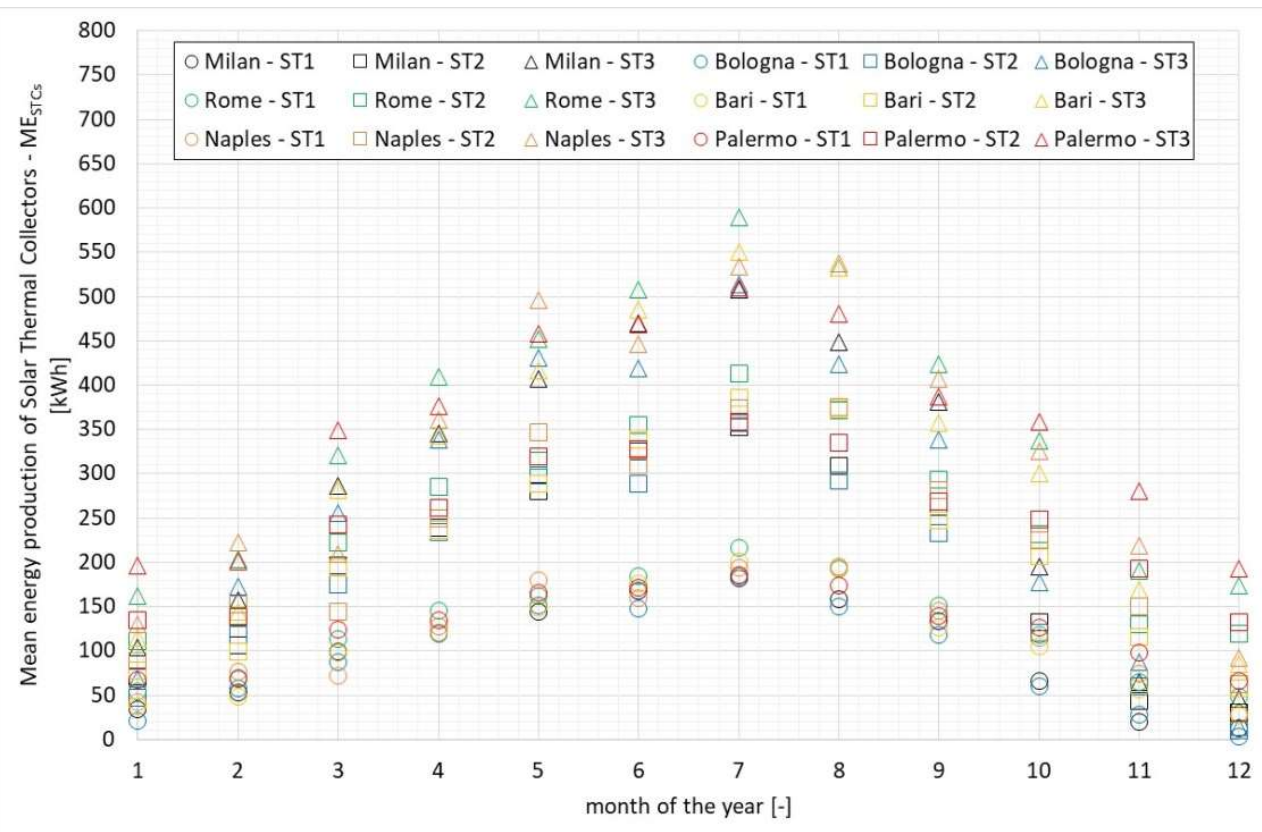

Fig. 2. MEstCs $[\mathrm{kWh}]$ for the selected locations and number of panel configurations.

Table 2. VDHW configurations: asset and tailored ratings.

\begin{tabular}{|c|c|c|c|c|c|}
\hline \multicolumn{3}{|c|}{ Asset Rating (AR) } & \multicolumn{3}{|c|}{ Tailored Rating (TR) } \\
\hline Configurations & Net area $\left[\mathrm{m}^{2}\right]$ & VDHW [l/day] & Configurations & People & VDHW [l/day] \\
\hline VDHW-A1 & 80 & 122 & \multirow{2}{*}{ VDHW-P1 } & \multirow{2}{*}{1} & \multirow{2}{*}{172} \\
\hline VDHW-A2 & 100 & 143 & & & \\
\hline $\mathrm{V}_{\text {DHW-A3 }}$ & 120 & 165 & \multirow{2}{*}{ VDHW-P2 } & \multirow{2}{*}{2} & \multirow{2}{*}{344} \\
\hline $\mathrm{V}_{\text {DHW-A4 }}$ & 135 & 181 & & & \\
\hline $\mathrm{V}_{\text {DHW-A5 }}$ & 168 & 216 & $V_{\text {DHW-P3 }}$ & 3 & 516 \\
\hline
\end{tabular}

Once defined all the inputs and the STC influencing factors, the analysis was developed as follows:

1. Normalization of the parametric energy simulation results for the $\mathrm{V}_{\text {DHWlim, }}$, the number of panels, the thermal energy produced by ST1 configuration in each simulated location, and the mean Climatic Parameter $\left(\mathrm{CP}_{\mathrm{m}}\right)$ calculated as the mean of the $\mathrm{CP}$ monthly values of each considered location;

2. Analysis of the normalized results and definition of the correction factor related to the number of panels $\left(\mathrm{F}_{\mathrm{STC}}\right)$; 
3. Definition of the mean energy supplied by the STCs in each month as a function of the $\mathrm{CP}_{\mathrm{m}}$;

4. Definition of the corrective factor as a function of the $\mathrm{V}_{\text {DHWlim; }}$;

5. Definition of the mathematical equation for the more reliable thermal energy produced by STC;

6. Evaluation of coverage percentage of the DHW by the STC system and the remaining DHW need to be covered by other TBSs;

7. Validation of the proposed mathematical equations with the energy simulation results carried out considering the $\mathrm{V}_{\mathrm{DHW}}$ values evaluated with the $\mathrm{AR}$ and the TR.

The normalization process is one of the most important steps in the analysis phase since makes it possible to extend the mathematical equation to different scenarios such as different climate conditions or $\mathrm{V}_{\mathrm{DHW}}$ values.

\section{Results}

As summarized in Fig. 1, the different configurations of the case studies were analysed by means of parametric energy simulations considering different climatic conditions, number of panels (ST1, ST2, and ST3), and a fixed $\mathrm{V}_{\text {DHWlim. }}$

The obtained $\mathrm{ME}_{\mathrm{STC}}$ values were then normalized by:

- $\quad \mathrm{V}_{\text {DHWlim }}(1,000 \mathrm{l} /$ day);

- number of panels adopted in each configuration;

- $\quad$ thermal energy supplied by the ST1 configuration for each location;

- $\quad \mathrm{CP}_{\mathrm{m}}$ defined in Section 2.

The normalized values of MEsTCs as function of the $\mathrm{CP}_{\mathrm{m}}$ are shown in Fig. 3 for all the configurations (ST1, ST2, and ST3) and for their average value $\left(\mathrm{ST}_{\mathrm{m}}\right)$.

Fig. 3 shows the same trend for all the configurations allowing introducing a correction factor for the energy supplied by the STCs $\left(\mathrm{F}_{\mathrm{STC}}\right)$ expressed by equation (4), which already takes the correction for the $\mathrm{V}_{\mathrm{DHWlim}}$ into account.

$$
F_{S T C}=1.5 \cdot C P_{m}^{-1.061}
$$

The monthly-normalized energy produced by the STCs was then weighted for the $\mathrm{CP}_{\mathrm{m}}$ obtaining the $\mathrm{ME}_{\mathrm{CPm}}$; this parameter is expressed by equation (5) on the basis of the considered month of the year $(m)$. Therefore, the $\mathrm{ME}_{\mathrm{CPm}}$ was calculated starting from the

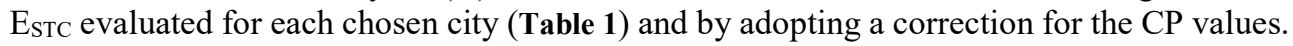

$$
M E_{C P_{m}}=0.0119 \cdot m^{5}-0.2664 \cdot m^{4}+1.3022 \cdot m^{3}+0.9988 \cdot m^{2}+14.553 \cdot m+27.286
$$

This equation allows calculating the mean thermal energy produced by STC for a standard location $\left(\mathrm{ME}_{\mathrm{CPm}}\right)$, i.e. for the one characterized by the same $\mathrm{CP}_{\mathrm{m}}$ calculated according to the step 1 of the analysis procedure described in section 2.2, and for the ST1 configuration. In order to calculate the thermal energy produced by STC in different locations and configurations, equation (5) should be corrected for the real $\mathrm{CP}$ and ST configuration. Specifically, the energy supplied by the STCs (ESTC) in each location and for different number of panels and values of the $\mathrm{V}_{\mathrm{DHW}}$ can be calculated through equation (6),

$$
E_{S T C}=\frac{M E_{C P m} \cdot C P_{\text {month }}}{C P_{m}} \cdot F_{S T C} \cdot n_{\text {panels }} \cdot F_{V_{D H W}}
$$


where $\mathrm{CP}_{\text {month }}$ is the monthly value of $\mathrm{CP}$ for each location, $\mathrm{n}_{\text {panels }}$ is the number of panels placed on the building, and $\mathrm{F}_{\mathrm{V}_{\mathrm{DHW}}}$ is a correction factor calculated by equation (7) as a function of the $V_{\text {DHWlim }}$ used for the parametric energy simulations, the $V_{\text {DHW }}$ values of both the AR and the TR approaches, and a constant.

$$
F_{V_{D H W}}=\left(\frac{859}{V_{D H W}{ }_{\text {lim }}-V_{D H W}}\right)
$$

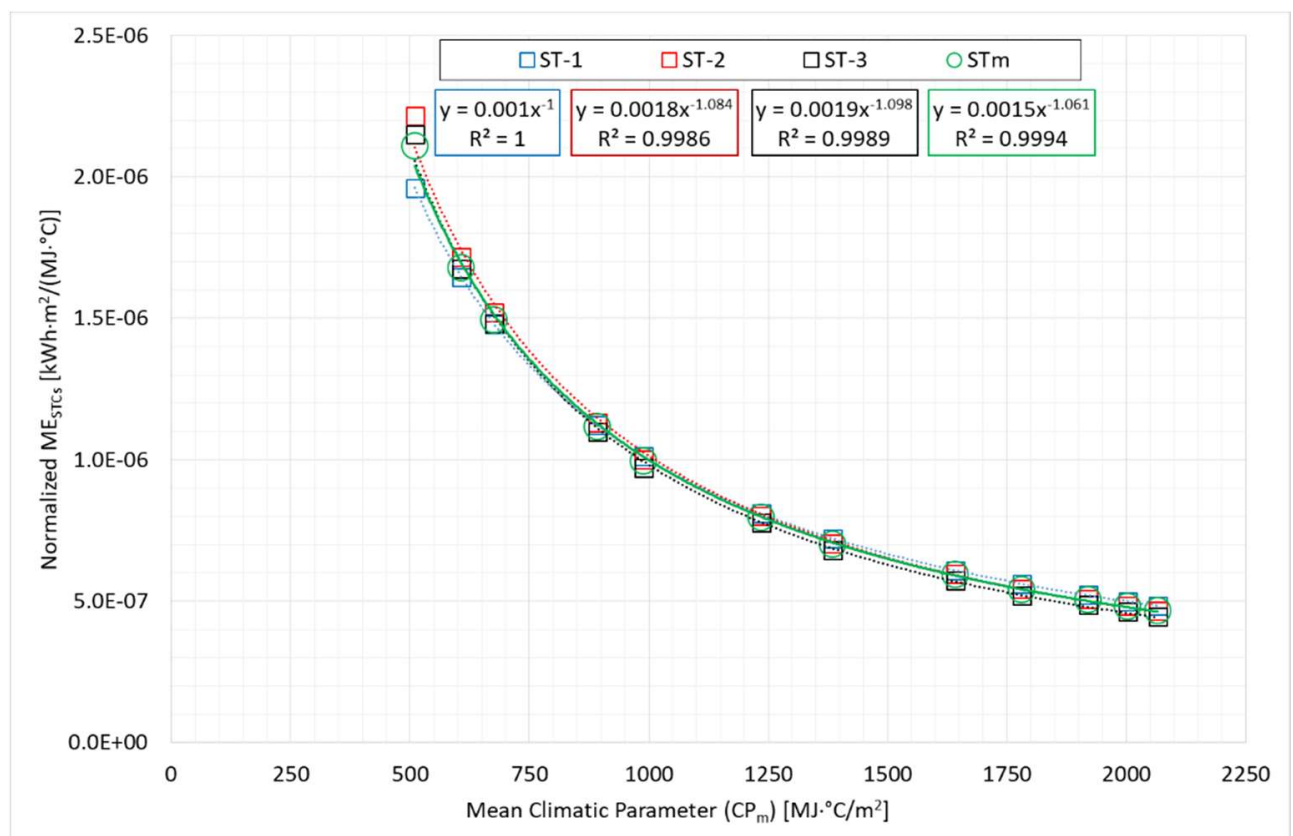

Fig. 3. Normalization of energy production $[\mathrm{kWh}]$ of STCs for the energy supplied by ST1 configuration, the number of panels, and the $\mathrm{CP}_{\mathrm{m}}$.

Combining equation (6) with the $\mathrm{V}_{\mathrm{DHw}}$ calculated with the AR or the TR (Table 2) and the primary energy for DHW evaluated according to the $\mathrm{AR}\left(\mathrm{EP}_{\mathrm{W} \text {-asset }}\right)$, the $\mathrm{V}_{\mathrm{DHW}}$ provided by the STC system ( $\mathrm{V}_{\text {DHW-STC }}$ ) can be approximated by equation (8). Consequently, the $\mathrm{V}_{\text {DHW }}$ to be covered by other TBSs ( $\left.\mathrm{V}_{\mathrm{DHW}-\mathrm{TBS}}\right)$ can be calculated as the difference between the $\mathrm{V}_{\mathrm{DHW}}$ and the $\mathrm{V}_{\text {DHW-STC. }}$

$$
V_{D H W-S T C}=\frac{E_{S T C} \cdot V_{D H W}}{E P_{W-a s s e t}}
$$

Finally, the reliability of equations (6) and (8) was also tested. In particular, the results of equation (6) were compared with the one returned by the energy simulations carried out considering the $\mathrm{V}_{\text {DHWlim }}$ (Fig. 4); the outcomes of equation (8), instead, were compared (Fig. 5 ) with the energy simulations results carried out considering the $V_{\text {DHW }}$ shown in Table 2 and calculated according to the AR and the TR.

Both the comparisons confirm the reliability of the proposed simplified approach for the evaluation of the thermal energy supplied by the STCs. The results in Fig. 4 and Fig. 5 highlight a good approximation of the energy supplied by the STCs and the one to be covered by other TBSs, respectively. More in detail, a good correlation was found with all the configurations $\left(\mathrm{R}^{2}>0.97\right)$; the ST3 shows the higher mean error in the coldest months, where the ESTC values are the lowers; however, this error was considered still acceptable. 


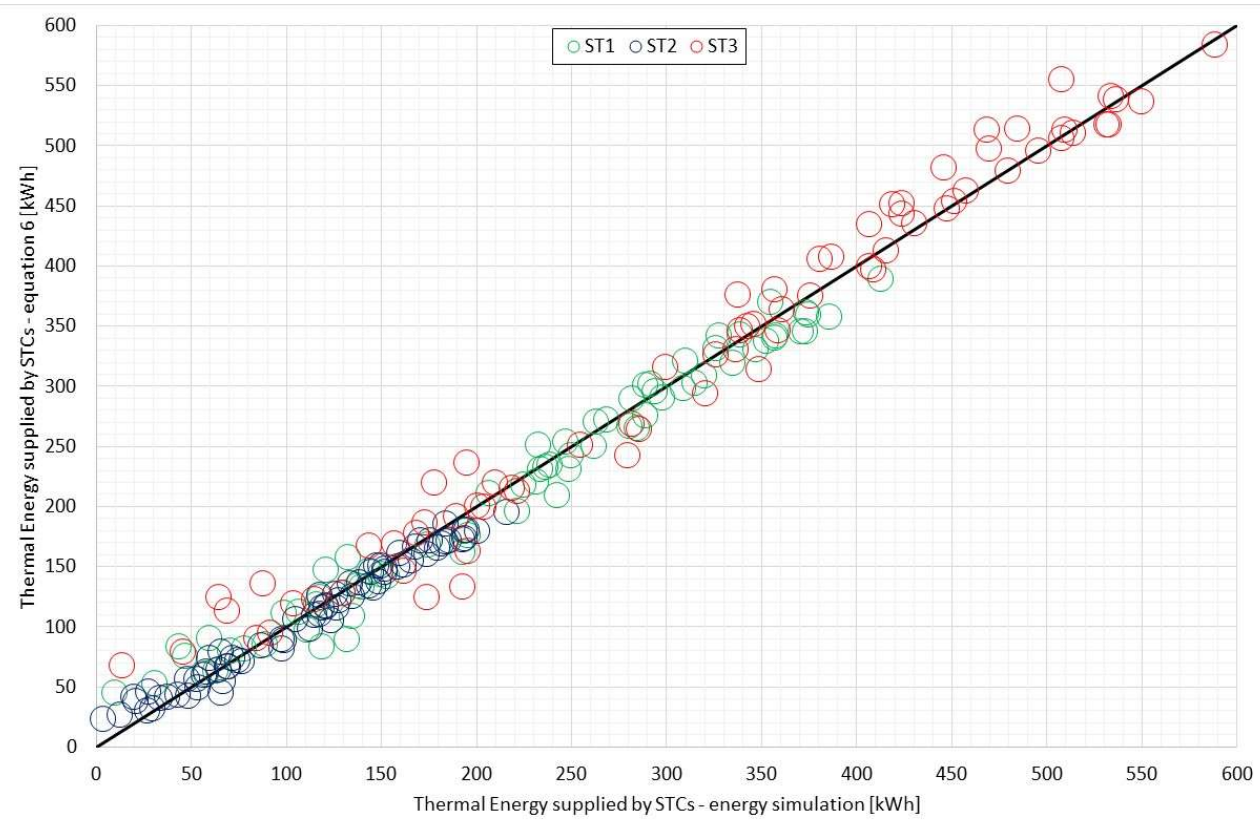

Fig. 4. Validation of the EsTC with energy simulation results.

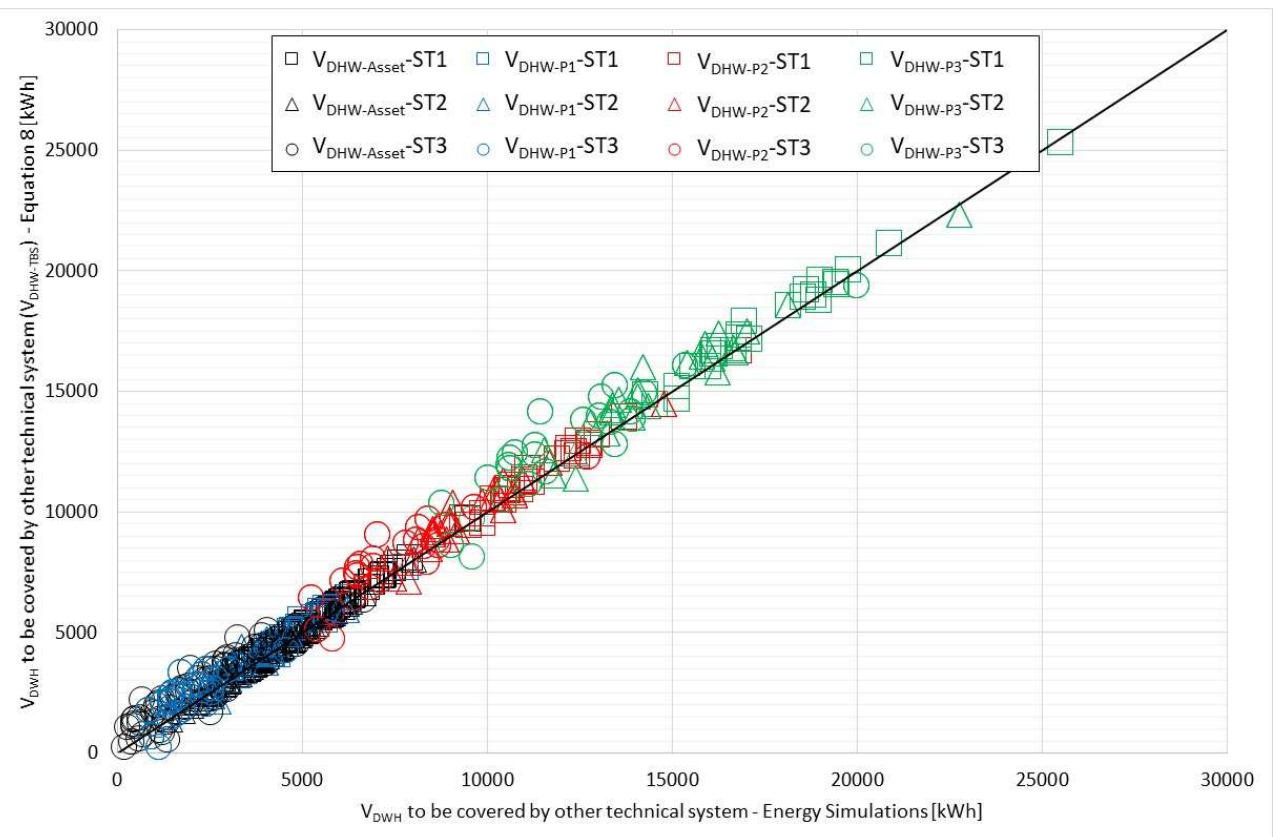

Fig. 5. Validation of the $V_{\text {TBS }}$ with energy simulation results.

According to the results, the proposed methodological approach can be considered reliable and effective for pre-dimensioning analyses especially when ST1 and ST2 configurations are adopted. Furthermore, thanks to the normalization, the equations can be applied to obtain the energy supplied by the STCs and the $V_{\text {DHW }}$ to be covered by other TBSs even for configurations not analyzed in the present paper. 
Finally, the monthly values of the $\mathrm{CP}_{\mathrm{m}}$, the $\mathrm{F}_{\mathrm{STC}}$ and the $\mathrm{ME}_{\mathrm{CPm}}$ to be used in equations (6) and (8) are reported in Table 3 . These values can be easily applied to obtain the ESTC and the $\mathrm{V}_{\mathrm{DHW}}$ in different climatic contexts and STC configurations.

Table 3. Monthly $\mathrm{CP}_{\mathrm{m}}$, F $\mathrm{F}_{\mathrm{STC}}$ and $\mathrm{ME}_{\mathrm{CPm}}$ values.

\begin{tabular}{|c|c|c|c|}
\hline Month & $\mathbf{C P}_{\mathrm{m}}\left[\mathbf{M J} \mathbf{J}^{\circ} \mathbf{\mathbf { m } ^ { 2 } ]}\right.$ & $\mathbf{F}_{\text {STC }}[-]$ & $\mathbf{M E}_{\mathbf{C P m}}[\mathbf{k W h}]$ \\
\hline January & 618 & 1.015 & 43.89 \\
\hline February & 947 & 0.991 & 66.93 \\
\hline March & 1,303 & 0.972 & 96.46 \\
\hline April & 1,678 & 0.955 & 129.00 \\
\hline May & 1,964 & 0.946 & 159.03 \\
\hline June & 2,039 & 0.943 & 180.38 \\
\hline July & 2,047 & 0.942 & 187.71 \\
\hline August & 1,797 & 0.950 & 177.95 \\
\hline September & 1,420 & 0.965 & 151.70 \\
\hline October & 1,000 & 0.985 & 114.72 \\
\hline November & 651 & 1.008 & 79.32 \\
\hline December & 528 & 1.025 & 65.84 \\
\hline
\end{tabular}

\section{Conclusions}

Solar thermal collector (STC) systems are one of the widely used solutions to employ Renewable Energy Sources (RES) especially in Domestic Hot Water (DHW) production. However, the calculation methodology provided by the current national regulation involves knowledge of several technical information, such as characteristics of STC panels, technical building system configuration, and outdoor thermal conditions.

The aim of this work is to provide a new simplified calculation methodology able to accurately assess the thermal energy need and the volume of DHW supplied by the STCs basing on a few information.

Several parametric simulations were carried out taking into account different configurations of the main factors that influence the thermal energy produced by the STCs: DHW volume needs, outdoor conditions, and number of the panels. The obtained outcomes were combined in order to return the simplified calculation methodology. Furthermore, the results were normalized in order to apply the proposed approach also to different scenarios not considered in the present work. Finally, the obtained equations were validated with the simulation results using different DHW volumes.

The results confirmed that the equations found in the present study are useful tools not only in STC initial analyses and STC pre-dimensioning, but also for the preliminary evaluation required for incentive assessment. Furthermore, the methodological approach used for defining the simplified calculation method opens to new and interesting future developments, such as its application to other energy services with the aim to define new calculation methods able to return more accurate results than the asset rating.

\section{References}

1. Gestore dei Servizi Energetici (GSE), Statistical Report 2019: Development and Diffusion of Renewable Energy Sources in Italy and in Europe, (2021) (in Italian) 
2. Gestore dei Servizi Energetici (GSE), Statistical Report 2019: Renewable Energy Sources in Italy in electric, thermal, and transportation sectors (2021) (in Italian)

3. Ministry of Economic Development, Ministry of the Environment and Protection of Natural Resources and the Sea, Ministry of Infrastructure and Transport, Integrated National Energy and Climate Plan (2019) (in Italian)

4. P. Valdiserri, C. Biserni. Energy Proced. 148 (2018)

5. S. D. Fertahi, T. Bouhal, F. Gargab, A. Jamil, T. Kousksou, A. Benbassou. Sol Energy, 160 (2018)

6. I. Harrabi, M. Hamdi, A. Bessifi, M. Hazami. J. Environ. Integr, 6 (2021)

7. T. T. Chow, Z. Dong, L. S. Chan, K. F. Fong, Y. Bai. Energy Build, 43 (2011)

8. M. Hazami, N. Naili, I. Attar, A. Farhat. Energy Convers Manag, 76, (2013)

9. C. N. Antoniadis, G. Martinopoulos. Renew Energy, 137 (2019)

10. M. Beccali, G. Leone, P. Caputo, S. Ferrari. Energy Proced, 91 (2016)

11. L. Mongibello, N. Bianco, M. Caliano, A. De Luca, G. Graditi. Energy Proced, 81 (2015)

12. M. Dongellini, S. Falcioni, G. L. Morini. Energy Proced, 82 (2015)

13. C. Hongbing, G. Yutong, N. Haoyu, Y. Xiaoli, C. Xilin. Energy Proced, 158 (2019)

14. UNI TS 11300 - Part 4, Energy Performance of Buildings - Renewable energy and other generation systems for space heating and domestic hot water production (2016) (in Italian)

15. UNI EN 15316-4-3, Energy Performance of Buildings - method for the calculation of energy demands and energy efficiency of systems. Productions systems, solar thermal collectors and photovoltaic systems (2018)

16. UNI TS 11300 - Part 1, Energy Performance of Buildings - Evaluation of energy need for space heating and cooling (2014) (in Italian)

17. UNI 10349, Heating and Cooling of Buildings. Mean monthly data for the thermalenergy performance evaluation of buildings and methods for calculating direct and diffused solar irradiances and the solar irradiance on sloping surface (2016)

18. Italian National Institute of Statistics (ISTAT). Database and census. Available online: http://dati.istat.it/

19. UNI TS 11300 - Part 2, Energy Performance of Buildings - Evaluation of primary energy need and of system efficiencies for space heating, domestic hot water production, ventilation and lighting for non-residential buildings (2019) (in Italian)

20. Caleffi S.p.A. Technical Focus on water and sanitary installations design (2015) (in Italian)

21. Caleffi S.p.A. Domestic hot water production: the danger of Legionella (1999) (in Italian) 